SFACIOTTE, R.A.P. et al. Efeito do período de armazenamento, local e tipo de tratamento sobre a qualidade de ovos brancos para consumo humano. PUBVET, Londrina, V. 8, N. 19, Ed. 268, Art. 1782, Outubro, 2014.

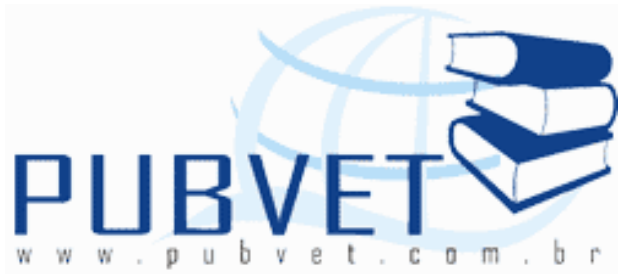

PUBVET, Publicações em Medicina Veterinária e Zootecnia.

\title{
Efeito do período de armazenamento, local e tipo de tratamento sobre a qualidade de ovos brancos para consumo humano
}

\section{Ricardo Antonio Pilegi Sfaciotte1, Maria José Baptista Barbosa², Sheila Rezler Wosiacki $^{2}$, Rejane Machado Cardozo ${ }^{2}$, Raquel Reis Martins ${ }^{3}$}

${ }^{1}$ Aluno de pós-graduação do Programa Ciência Animal da Universidade Federal do Paraná - Setor Palotina/PR

${ }^{2}$ Professora doutora do curso de Medicina Veterinária da Universidade Estadual de Maringá, campus Umuarama

3 Professora assistente do curso de Medicina Veterinária da Universidade Estadual de Maringá, campus Umuarama

\section{Resumo}

A qualidade dos ovos é determinada por aspectos externos, sendo eles relacionados com a qualidade da casca quanto a sua estrutura e higiene, e os aspectos internos, tais como as características relativas à gema, câmara de ar, albúmen, cor, odor e sabor, sendo que, o conjunto dessas características acarreta na aceitabilidade do produto pelos consumidores. O tempo de estocagem e a temperatura dos ovos têm grande influência para indicar a qualidade do ovo. Com isso, o objetivo desse trabalho foi avaliar o efeito do período em dias e local de armazenamento e tipo de tratamento (lavagem e imersão com óleo mineral) na qualidade externa e interna dos ovos brancos de poedeiras comerciais para consumo humano. Os tratamentos consistiram em 
SFACIOTTE, R.A.P. et al. Efeito do período de armazenamento, local e tipo de tratamento sobre a qualidade de ovos brancos para consumo humano. PUBVET, Londrina, V. 8, N. 19, Ed. 268, Art. 1782, Outubro, 2014.

seis (6) períodos de armazenamento ( $0,7,14,21,28$ e 35 dias), dois (2) locais de armazenamento (geladeira e ambiente) e três (3) tipos de tratamento (lavados com água corrente, não lavados e pincelados na extremidade mais larga com óleo mineral). As variáveis estudadas foram o peso do ovo, altura do albúmen, altura e largura da gema. Nesse estudo, observou-se que independente dos tratamentos (ovos lavados, não lavados e pincelados com óleo mineral), os ovos conservados em geladeira foram superiores $(P \leq 0,05)$ em qualidade para altura da gema e altura do albúmen, comparando com o ambiente. Para a largura da gema e o peso dos ovos, os efeitos foram variados. Assim, concluiu-se por meio deste ensaio que os ovos perdem suas propriedades qualitativas ao longo do tempo, caso não sejam conservados em condições de baixa temperatura, independente se forem pincelados com óleo, lavados com água corrente ou não.

Palavras-chave: albúmen, peso, qualidade, estocagem, temperatura

\section{Effect of the period of storage, place and type of treatment on the quality of white eggs for human consumption}

\section{Abstract}

The quality of the eggs is determined by external aspects, they are related to the quality of the bark as its structure and hygiene, and the internal aspects such as the characteristics of the yolk, the air chamber, albumen, color, odor and taste, being that all of these characteristics leads to the acceptability of the product by consumers. The time of storage and temperature of the eggs has great influence to indicate the quality of the egg. Thus, the aim of this study was to evaluate the effect of time in days and the storage location and type of treatment (washing and immersion with mineral oil) in the external and internal quality of white eggs of laying hens for human consumption. The treatments consisted of six (6) storage periods (0,7, 14, 21, 28 and 35), two (2) local storage (refrigerator and environment) and three (3) types of treatment (washed with water current, not washed and brushed the wider end 
SFACIOTTE, R.A.P. et al. Efeito do período de armazenamento, local e tipo de tratamento sobre a qualidade de ovos brancos para consumo humano. PUBVET, Londrina, V. 8, N. 19, Ed. 268, Art. 1782, Outubro, 2014.

with mineral oil). The variables studied were egg weight, albumen height, yolk height and width. In this study, we observed that independent of treatment (washed eggs, not washed and brushed with mineral oil), preserved in refrigerator were higher $(P \leq 0.05)$ in quality for highegg yolk and height albumen, compared with the environment. For the width of the yolk and egg weight, the effects were varied. Thus, it was concluded that by means of this test the eggs lose their qualitative properties over time if they are not kept in low temperature conditions, whether they are brushed with oil, cleaned with running water or not.

Keywords: albumen, weight, quality, storage, temperature

\section{INTRODUÇÃO}

O ovo de galinha (Gallus domesticus) é considerado um dos alimentos mais completos da natureza, sendo estimadoo alimento de maior valor biológico apresentando uma composição rica em vitaminas ( $A$ e $B$, além das vitaminas $\mathrm{D}, \mathrm{E}$ e $\mathrm{K}$ ), minerais, ácidos graxos e proteínas, tendo todos os aminoácidos essenciais necessários à nutrição humana (RÊGO et al., 2012; MARINHO, 2011; BARBOSA et al., 2008), além de ser um dos alimentos de mais baixo custo e fácil produção, permitindo o aumento do consumo de um alimento de alto valor nutricional pela população de baixa renda (PASCOAL et al., 2008).

Devido ao baixo custo, o ovo faz parte do hábito alimentar dos brasileiros, estando presente, segundo a União Brasileira de Avicultores (UBA), na dieta de $99 \%$ das famílias brasileiras. Porem, apesar desses dados, o consumo médio de ovos no Brasil está abaixo dos Estados Unidos, México e Colômbia (UBA, 2013).

A produção de ovos aumenta a cada ano e, consequentemente, a busca para seuaprimoramento e novas tecnologias (CRUZ et al., 2009). Segundo a WorldPoultry (2012), o Brasil está em 40 lugar na produção de ovos no mundo, com 18 milhões de aves alojadas em todo país, atrás dos Estados Unidos (102 milhões), México (41 milhões) e Ucrânia (22 milhões), sendo que a maior 
SFACIOTTE, R.A.P. et al. Efeito do período de armazenamento, local e tipo de tratamento sobre a qualidade de ovos brancos para consumo humano. PUBVET, Londrina, V. 8, N. 19, Ed. 268, Art. 1782, Outubro, 2014.

parte dos ovos comercializados no Brasil é produzida por galinhas poedeiras comerciais, híbridas, de alto potencial genético, criadas em gaiolas, com elevada eficiência de produção de ovos e com alta tecnologia.

A produção de ovos no Brasil vem crescendo a cada ano, sendo que no ano de 2011 foi produzido aproximadamente 2,6 bilhões de dúzias, tendo um aumento de 4,3\% em relação ao ano de 2010 (2,4 bilhões). O estado de São Paulo é o maior produtor de ovos do Brasil seguido pelos estados de Minas Geras e Paraná, sendo responsáveis por 35,5\%, 11,4\% e 9,2\% da produção, respectivamente. Em 2011, o consumo brasileiro per capita por habitante ano foi de 163 ovos, tendo um aumento de $21 \%$ em relação ao ano de 2010 , que foi de 148,8 ovos. (UBA, 2012).

A qualidade dos ovos é determinada por aspectos externos, sendo eles relacionados com a qualidade da casca quanto a sua estrutura e higiene, e os aspectos internos, tais como as características relativas à gema, câmara de ar, albúmen, cor, odor e sabor, sendo que, o conjunto dessas características acarreta na aceitabilidade do produto pelos consumidores (MENDES, 2010).

O principal objetivo após a ovipostura é preservar ao máximo a qualidade original do ovo até que ele chegue ao consumidor, sendo que um armazenamento adequado realizado pelo consumidor também é de suma importância. A perda de água por meio dos poros da casca através da evaporação é a principal alteração da qualidade do ovo, sendo que essa evaporação está diretamente ligada ao ambiente em que o ovo é estocado, a umidade relativa, a ventilação e principalmente a temperatura(LEANDRO et al., 2005; MORENG e AVENS, 1990). Quando esses fatores estão associados acarretam em alterações físicas, químicas e funcionais das proteínas do ovo (ALLEONI e ANTUNES, 2001)

O emprego de tecnologias adequadas para prolongar a vida útil do ovo e de seus derivados logo após a postura é extremamente importante (SEIBEL, 2005), sendo que, de acordo com Lopes et al (2012), a refrigeração prolonga o tempo de validade dos ovos para o consumo em até 25 dias, porem, segundo Pascoal et al. (2008), a maioria dos ovos "in natura" comercializados no Brasil 
SFACIOTTE, R.A.P. et al. Efeito do período de armazenamento, local e tipo de tratamento sobre a qualidade de ovos brancos para consumo humano. PUBVET, Londrina, V. 8, N. 19, Ed. 268, Art. 1782, Outubro, 2014.

são desprovidos de refrigeração, e com isso, sofrem deterioração em no máximo 15 dias.

É aconselhável que os ovos saiam da sala de processamento da granja e já sejam refrigerados em temperatura média de $0^{\circ} \mathrm{C}$ a $4^{\circ} \mathrm{C}$, garantindo ao consumidor um produto nutritivo, saboroso, saudável e seguro (CARVALHO et al., 2003). No entanto, a refrigeração não é uma prática assegurada por lei e com isso no comércio ela não ocorre devido a altos custos, mas alguns estabelecimentos armazenam os ovos próximos a verduras e freezer na intenção de minimizar a temperatura (FREITAS, 2011).

O tempo de estocagem e a temperatura dos ovos tem grande influencia na qualidade do albúmen e da gema (BERARDINELLI et al., 2003), sendo que a altura do albúmen, o índice de área do albúmen e a porcentagem de clara espessa e fina também são usados para indicar a qualidade do ovo (ALLEONI e ANTUNES, 2001).

Vários atributos de qualidade da gema também são perdidos com o armazenamento prolongado dos ovos. Durante a estocagem, a gema fixa água do albúmen, tornando-se descentralizada e menos densa (ORDÓNEZ, 2005). De acordo com Solomon (1997) gemas de ovos velhos são achatadas, flácidas, podendo apresentar manchas escuras. A membrana vitelina, que circunda a gema, rompe-se com facilidade, deixando escorrer o conteúdo, o que prejudica a sua utilização.

Outra característica utilizada para determinar a qualidade do ovo é o peso, sendo influenciado pelo tempo de armazenamento (ANDRADE, 1975) e mesmo quando os ovos são submetidos à ambientes controlados de temperatura e umidade (MOURA, et al. 2008). Segundo Santos (2009), a perda de peso dos ovos acontece devido a diminuição de agua do albúmen, pois a proporção do mesmo diminui linearmente com o tempo de armazenamento ocorrendo um aumento linear na porcentagem da gema.

A qualidade de ovos frescos é determinada, principalmente, por meio do cálculo da unidade Haugh (UH) que é baseada na altura do albúmen denso corrigido para o peso do ovo (ALLEONI e ANTUNES, 2001). Segundo Figueiredo 
SFACIOTTE, R.A.P. et al. Efeito do período de armazenamento, local e tipo de tratamento sobre a qualidade de ovos brancos para consumo humano. PUBVET, Londrina, V. 8, N. 19, Ed. 268, Art. 1782, Outubro, 2014.

et al. (2011) esta análise dá uma indicação da duração e das condições de armazenamento dos ovos, sendo que quanto maior o valor da unidade Haugh, melhor a qualidade do ovo. Porem, a legislação brasileira não utiliza a essa unidade como parâmetro de avaliação da qualidade interna de ovos, mas países como os EUA classificam ovos comerciais em quatro classes de qualidade: excelente: tipo AA (100 até 72$)$, boa: tipo A (71 até 60$)$, mediana: tipo B (59 até 30) e baixa qualidade: tipo C (29 até 0) (USDA, 2000).

O uso da unidade Haugh tem recebido críticas quanto à sua utilização, devido à correção do peso do ovo, pois ao comparar ovos frescos entre diferentes idades e linhagens de poedeiras ou ovos armazenados em diferentes períodos, esse método se torna inadequado. Devido a isso, alguns autores sugerem a utilização da unidade Haugh somente em ovos frescos de poedeiras de mesma linhagem e idade (SILVERSIDES et al. 1993; ALLEONI e ANTUNES, 2001).

Algumas substâncias, como óleos minerais e vegetais, aplicadas na superfície da casca dos ovos preservam a qualidade interna, bem como estende a vida útil dos ovos, pois elas tendem a fechar os poros da casca evitando assim a evaporação de água, uma vez que os ovos tem sido comercializados "in natura" e sem refrigeração (SILVA et al.; 2010; WAIMALEONGORA-EK et al., 2009; CANER, 2005).

O processo de lavagem dos ovos é influência positiva à aceitação do produto pelo consumidor, uma vez que melhora a aparência para comercialização (LLOBET et al., 1989). Segundo Scatolini-Silva et al. (2013)a lavagem dos ovos causa danos a película de proteção natural da casca do ovo, favorecendo maiores liberações de agua e gases através dos poros, acarretando assim um maior índice de perda de peso do ovo.

Diversos trabalhos têm sido publicados avaliando o efeito de recobrimentos biodegradáveis na qualidade de ovos, como proteínas do soro de leite, quitosana, glúten de trigo, zeína de milho, entre outros (WAIMALEONGORA-EK et al., 2009; CANER, 2005). Entretanto, tais 
SFACIOTTE, R.A.P. et al. Efeito do período de armazenamento, local e tipo de tratamento sobre a qualidade de ovos brancos para consumo humano. PUBVET, Londrina, V. 8, N. 19, Ed. 268, Art. 1782, Outubro, 2014.

recobrimentos apresentam alto custo e envolvem materiais ou técnicas de difícil acesso na própria propriedade para a maioria dos pequenos produtores.

Entre materiais de fácil obtenção, Silva et al. (2010) avaliaram o efeito da utilização da cobertura com fécula de mandioca, mas verificaram que o uso de uma suspensão com $5 \%$ de fécula de mandioca não foi eficiente no retardamento do envelhecimento de ovos. Os autores sugeriram, dessa forma, a realização de mais estudos para a avaliação de tecnologias acessíveis visando manter a qualidade de ovos.

Neste sentido, o recobrimento com óleo mineral pode ser uma alternativa viável para aumentar o tempo de vida de prateleira de ovos, sendo assim, o objetivo desse trabalho foi avaliar o efeito do período em dias e local de armazenamento e tipo de tratamento (lavagem e imersão com óleo mineral) na qualidade externa e interna dos ovos brancos de poedeiras comerciais para consumo humano.

\section{MATERIAIS E MÉTODOS}

O experimento foi conduzido no Laboratório de Alimentos do curso de Medicina Veterinária/UEM, campus de Umuarama. Os ovos foram coletados em uma granja comercial ovipostos no dia do início do experimento, classificados como tipo grande, 55 a 60 gramas (Resolução CIPOA n5/91). Os tratamentos consistiram em seis (6) períodos de armazenamento (0, 7, 14, 21, 28 e 35 dias), dois (2) locais de armazenamento (geladeira e ambiente) e três (3) tipos de tratamento (lavados com água corrente, não lavados e pincelados na extremidade mais larga com óleo mineral).

As variáveis estudadas foram o peso do ovo, altura do albúmen, altura e largura da gema. Os ovos foram pesados em uma balança analítica e, com o auxílio de um paquímetro digital, foram medidos a altura do albúmen, altura e largura da gema no dia zero (0). Os ovos restantes foram colocados em bandejas de polpa de papel e armazenados de acordo com os tratamentos (ambiente e geladeira). Os ovos foram divididos em três (3) grupos, sendo um lavado com água corrente, o outro foi pincelado com óleo mineral na parte 
SFACIOTTE, R.A.P. et al. Efeito do período de armazenamento, local e tipo de tratamento sobre a qualidade de ovos brancos para consumo humano. PUBVET, Londrina, V. 8, N. 19, Ed. 268, Art. 1782, Outubro, 2014.

mais larga do ovo e o ultimo não foi lavado e nem pincelado com óleo. Os ovos do grupo da geladeira ficaram em uma temperatura em torno de dois (2) a quatro (4) ${ }^{\circ} \mathrm{C}$. Os do grupo ambiente foram colocados em uma gôndola, onde a temperatura variou de $17^{\circ} \mathrm{C}$ a $32^{\circ} \mathrm{C}$.

O delineamento experimental foi inteiramente casualizado, com esquema fatorial $6 \times 2 \times 3$ (tempo de armazenamento $\times$ local de armazenamento $\times$ tipos de tratamento) com seis (6) repetições. Os efeitos do tempo de armazenamento foram avaliados por regressão polinomial a $5 \%$ de probabilidade e o parâmetro utilizado para o ajuste das equações foi o R2 próximo de 1 .

$O$ efeito de local de armazenamento e o efeito do tipo de armazenamento foram avaliados pelo Teste de Tukey a $5 \%$ de probabilidade. A variância durante a condição do ensaio foi associada a efeitos aleatórios (local de armazenamento) e 2 fixos (tempo de armazenamento e tipo de tratamento). Utilizou-se o software SAEG para as análises.

\section{RESULTADO E DISCUSSÃO}

De acordo com a tabela 1, referente aos resultados em relação ao peso e a altura do albúmen dos ovos tanto refrigerado como em temperatura ambiente, os ovos que permaneceram em temperatura ambiente, porém pincelados com óleo mineral, tiveram diminuição na altura do albúmen $(5,42 \mathrm{~mm}-1,41 \mathrm{~mm})$ (gráfico 1), mas o peso não sofreu influencia ( $P>0,05)$, assim como ocorrido com os ovos que não foram lavados e nem pincelados com óleo mineral (gráfico 2). Já os ovos que foram lavados com água corrente, também apresentaram uma diminuição na altura do albúmen $(5,19 \mathrm{~mm}-1,13 \mathrm{~mm}$ ) (gráfico 3), porem o peso do ovo foi influenciado $(P \leq 0,05)$ nas três ultimas semanas de análise, demonstrando que sem a proteção da camada de mucina na casca há uma maior desidratação do ovo. 
SFACIOTTE, R.A.P. et al. Efeito do período de armazenamento, local e tipo de tratamento sobre a qualidade de ovos brancos para consumo humano. PUBVET, Londrina, V. 8, N. 19, Ed. 268, Art. 1782, Outubro, 2014.

Tabela 1 - Peso $(\mathrm{g})$ e altura do albúmen $(\mathrm{mm})$ de ovos armazenados em geladeira e ambiente, submetidos a diferentes tratamentos (lavados, não lavados e pincelados com óleo mineral) por um período de 35 dias

\begin{tabular}{|c|c|c|c|c|c|c|}
\hline \multicolumn{4}{|c|}{ Peso dos Ovos $(\mathrm{g})$} & \multicolumn{3}{|c|}{ Altura do Albúmen (mm) } \\
\hline & \multicolumn{3}{|c|}{ Local de Armazenamento ${ }^{2}$} & \multicolumn{3}{|c|}{ Local de Armazenamento } \\
\hline Tratamento $^{1}$ & Geladeira & Ambiente & & Geladeira & Ambiente & \\
\hline & \multicolumn{5}{|c|}{$\begin{array}{l}\text { DIA O } \\
\text { MÉDIA }\end{array}$} & MÉDIA \\
\hline Óleo & $61,27 \mathrm{Aa}$ & $59,75 \mathrm{Aa}$ & 60,51 & 5,53 Aa & $5,42 \mathrm{Aa}$ & 5,47 \\
\hline Lavado & $59,26 \mathrm{Aa}$ & $57,60 \mathrm{Aa}$ & 58,43 & $5,48 \mathrm{Aa}$ & $5,19 \mathrm{Aa}$ & 5,33 \\
\hline Não Lavado & $60,41 \mathrm{Aa}$ & $59,57 \mathrm{Aa}$ & 59,99 & 5,44 Aa & $5,36 \mathrm{Aa}$ & 5,40 \\
\hline MÉDIA & 60,31 & 58,97 & & 5,48 & 5,32 & \\
\hline \multicolumn{7}{|c|}{ DIA 7} \\
\hline Óleo & $64,39 \mathrm{Aa}$ & $59,14 \mathrm{Ab}$ & 61,76 & 4,92 Aa & $3,38 \mathrm{Ab}$ & 4,15 \\
\hline Lavado & $60,30 \mathrm{Ba}$ & $57,85 \mathrm{Aa}$ & 59,07 & $3,98 \mathrm{Aa}$ & $2,01 \mathrm{Bb}$ & 2,99 \\
\hline $\begin{array}{c}\text { Não } \\
\text { Lavado }\end{array}$ & $59,69 \mathrm{Ba}$ & $55,97 \mathrm{Ab}$ & 57,83 & 4,93 Aa & $2,27 \mathrm{Bb}$ & 3,60 \\
\hline MÉDIA & 61,46 & 58,04 & & 4,61 & 2,55 & \\
\hline \multicolumn{7}{|c|}{ DIA 14} \\
\hline Óleo & $61,07 \mathrm{Aa}$ & $58,52 \mathrm{Aa}$ & 59,79 & 5,87 Aa & $2,43 \mathrm{Bb}$ & 4,15 \\
\hline Lavado & $61,30 \mathrm{Aa}$ & $57,80 \mathrm{Ab}$ & 59,55 & $3,98 \mathrm{Ba}$ & 3,47 Aa & 3,72 \\
\hline $\begin{array}{c}\text { Não } \\
\text { Lavado }\end{array}$ & $60,74 \mathrm{Aa}$ & $57,14 \mathrm{Ab}$ & 58,94 & $4,19 \mathrm{Ba}$ & $1,90 \mathrm{Bb}$ & 3,04 \\
\hline MÉDIA & 61,03 & 57,82 & & 4,68 & 2,55 & \\
\hline \multicolumn{7}{|c|}{$\begin{array}{l}\text { DIA } 21 \\
\end{array}$} \\
\hline Óleo & $59,02 \mathrm{Aa}$ & $58,50 \mathrm{Aa}$ & 58,76 & $4,08 \mathrm{Ba}$ & $2,92 \mathrm{Ab}$ & 3,50 \\
\hline Lavado & $62,40 \mathrm{Aa}$ & $55,03 \mathrm{Ab}$ & 58,72 & $5,37 \mathrm{Aa}$ & $1,20 \mathrm{Bb}$ & 3,28 \\
\hline $\begin{array}{c}\text { Não } \\
\text { lavado }\end{array}$ & $59,30 \mathrm{Aa}$ & 56,35 Aa & 53,83 & $4,70 \mathrm{ABa}$ & $2,17 \mathrm{Ab}$ & 3,43 \\
\hline MÉDIA & 60,24 & 56,71 & & 4,71 & 2,09 & \\
\hline \multicolumn{7}{|c|}{ DIA 28} \\
\hline Óleo & $58,68 \mathrm{Aa}$ & $57,55 \mathrm{Aa}$ & 58,12 & $4,72 \mathrm{Aa}$ & $2,18 \mathrm{Ab}$ & 3,45 \\
\hline Lavado & $56,37 \mathrm{Aa}$ & $56,33 \mathrm{Aa}$ & 56,35 & $5,29 \mathrm{Aa}$ & $1,46 \mathrm{Ab}$ & 3,37 \\
\hline $\begin{array}{c}\text { Não } \\
\text { lavado }\end{array}$ & $58,10 \mathrm{Aa}$ & $55,48 \mathrm{Aa}$ & 56,79 & $4,85 \mathrm{Aa}$ & $1,56 \mathrm{Ab}$ & 3,20 \\
\hline MÉDIA & 57,71 & 56,45 & & 4,95 & 1,73 & \\
\hline \multicolumn{7}{|c|}{ DIA 35} \\
\hline Óleo & $56,95 \mathrm{Ab}$ & $60,75 \mathrm{Aa}$ & 58,85 & $5,19 \mathrm{Aa}$ & $1,41 \mathrm{Ab}$ & 3,30 \\
\hline Lavado & $57,36 \mathrm{Aa}$ & $55,40 \mathrm{Ba}$ & 56,38 & $5,36 \mathrm{Aa}$ & $1,13 \mathrm{Ab}$ & 3,24 \\
\hline $\begin{array}{c}\text { Não } \\
\text { lavado }\end{array}$ & $60,41 \mathrm{Aa}$ & $59,57 \mathrm{Ba}$ & 59,99 & $4,19 \mathrm{Ba}$ & $1,63 \mathrm{Ab}$ & 2,91 \\
\hline Média & 58,24 & 58,57 & & 4,91 & 1,39 & \\
\hline CV (\%) & \multicolumn{3}{|c|}{5,00} & \multicolumn{2}{|c|}{18,94} & \\
\hline
\end{tabular}

${ }^{1}$ Médias seguidas de mesma letra maiúscula, em cada coluna, não diferem entre si pelo teste de Tukey, a $5 \%$ de probabilidade. ${ }^{2}$ Médias seguidas de mesma letra minúscula, em cada linha, não diferem entre si pelo teste $\mathrm{F}$, a $5 \%$ de probabilidade. 
SFACIOTTE, R.A.P. et al. Efeito do período de armazenamento, local e tipo de tratamento sobre a qualidade de ovos brancos para consumo humano. PUBVET, Londrina, V. 8, N. 19, Ed. 268, Art. 1782, Outubro, 2014.

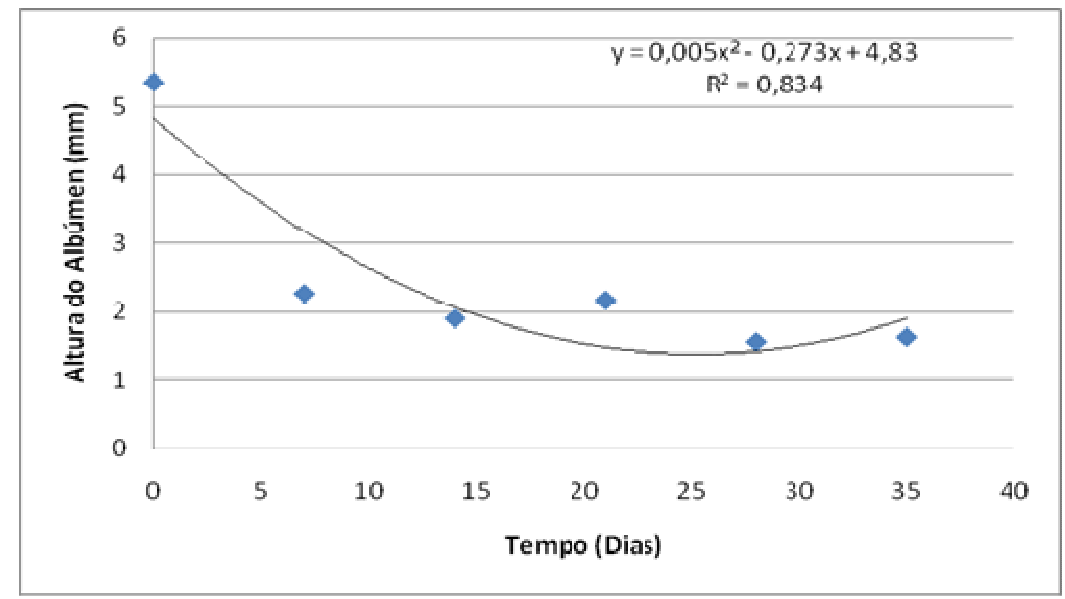

Gráfico 1: Altura do albúmen $(\mathrm{mm})$ de ovos armazenados em ambiente e pincelados com óleo mineral no período de 35 dias.

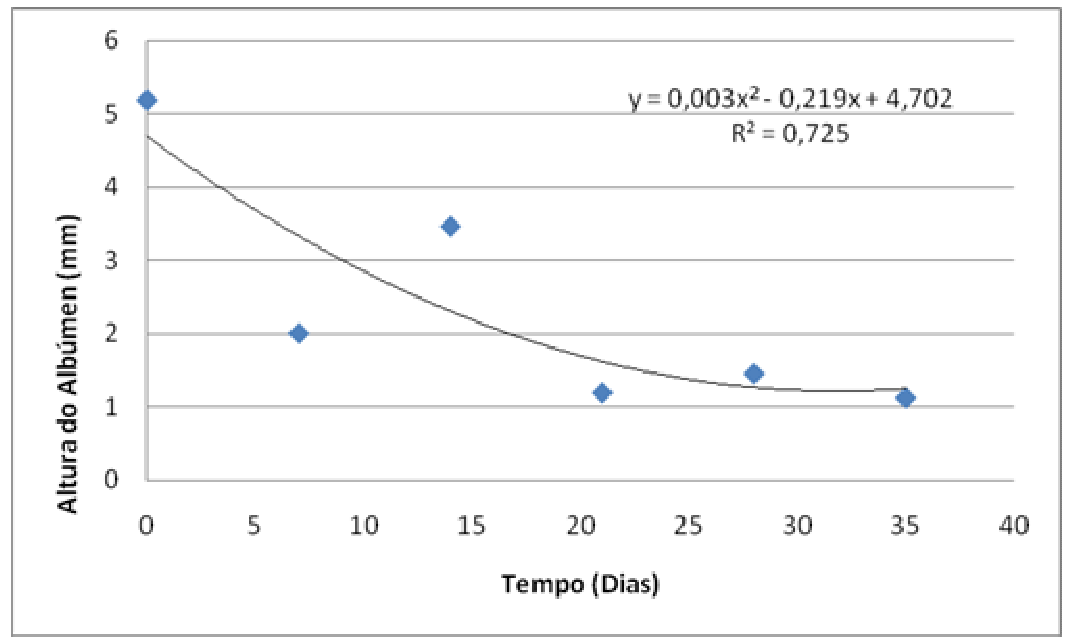

Gráfico 2: Altura do albúmen (mm) de ovos armazenados em ambiente e sem serem lavados com água corrente ou pincelados com óleo mineral no período de 35 dias. 
SFACIOTTE, R.A.P. et al. Efeito do período de armazenamento, local e tipo de tratamento sobre a qualidade de ovos brancos para consumo humano. PUBVET, Londrina, V. 8, N. 19, Ed. 268, Art. 1782, Outubro, 2014.

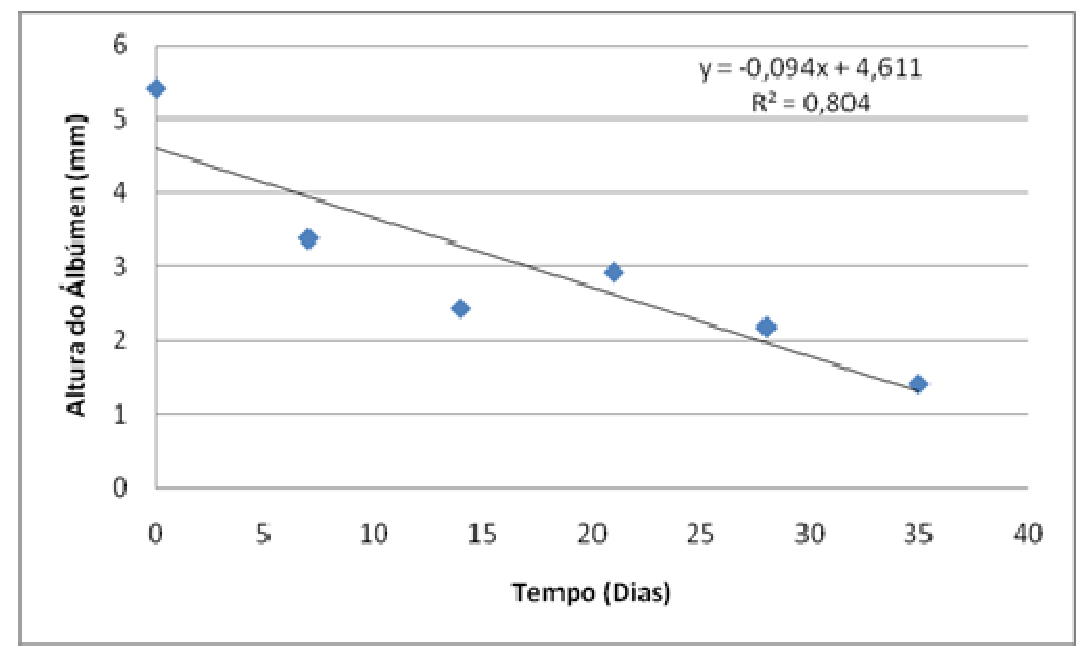

Gráfico3: Altura do albúmen (mm) de ovos armazenados em ambiente e lavados com água corrente no período de 35 dias.

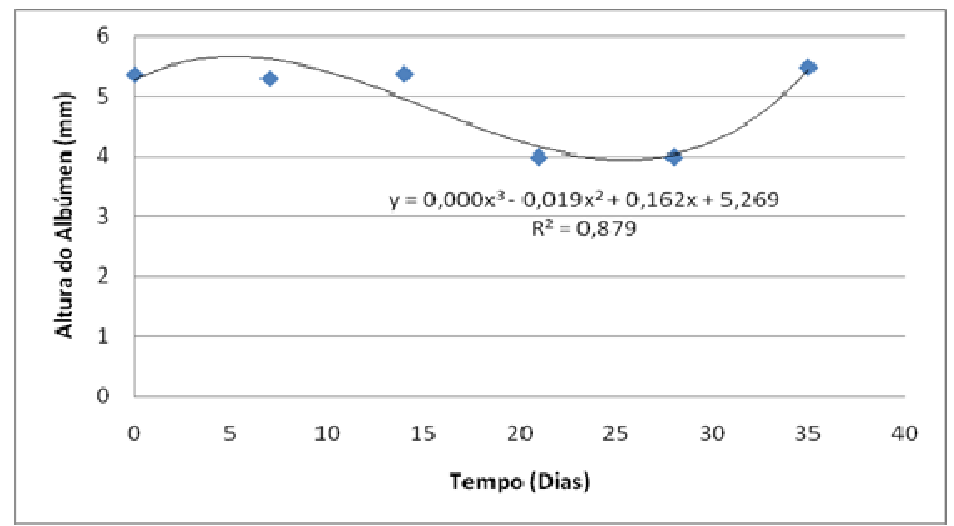

Gráfico 4: Altura do albúmen ( $\mathrm{mm}$ ) de ovos armazenados em geladeira e lavados com água corrente no período de 35 dias.

Os ovos que foram armazenados em geladeira, $2^{\circ} \mathrm{C}-4^{\circ} \mathrm{C}$, não demonstraram alterações na altura do albúmen durante o período de estudo (35 dias) em nenhum dos tratamentos (pincelados com óleo mineral, lavados e ovos não lavados e não pincelados com óleo mineral) (gráfico 4 e 5), já o peso começou a diminuir a partir da 
SFACIOTTE, R.A.P. et al. Efeito do período de armazenamento, local e tipo de tratamento sobre a qualidade de ovos brancos para consumo humano. PUBVET, Londrina, V. 8, N. 19, Ed. 268, Art. 1782, Outubro, 2014.

segunda e terceira semana nos ovos pincelados com óleo mineral (gráfico 6) e nos ovos lavados com água corrente (gráfico 7) respectivamente, pois de acordo com Scatolini-Silva et al. (2013), a higienização do ovo proporciona uma queda em sua qualidade.

Segundo Pombo (2003), ao estudar o efeito do tratamento térmico de ovos inteiros na perda de peso e características de qualidade interna,verificou que as trocas gasosas são responsáveis pela liquefação do albúmen e,consequentemente, em um ovo estocado, a gema absorve água deste albúmen liquefeito.

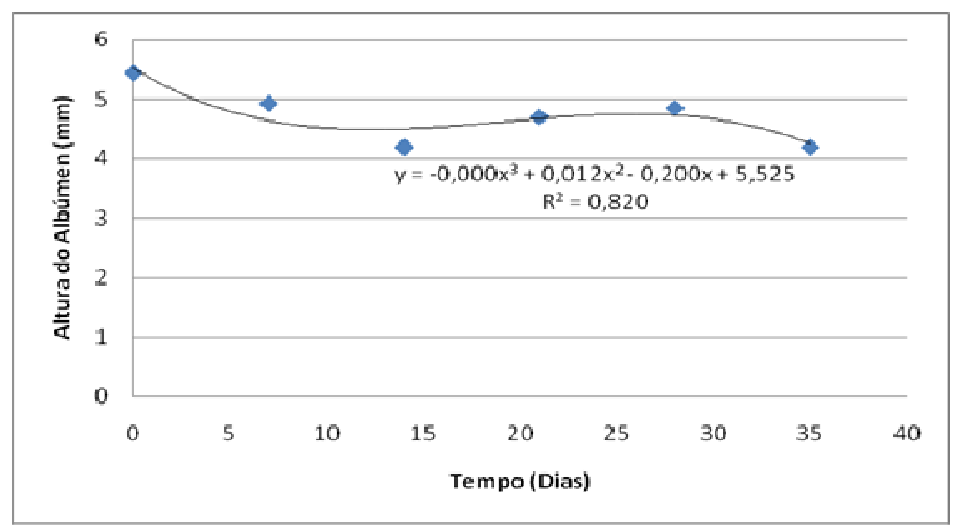

Gráfico 5: Altura do albúmen ( $\mathrm{mm}$ ) de ovos armazenados em geladeira e sem serem lavados com água corrente ou pincelados com óleo mineral no período de 35 dias.

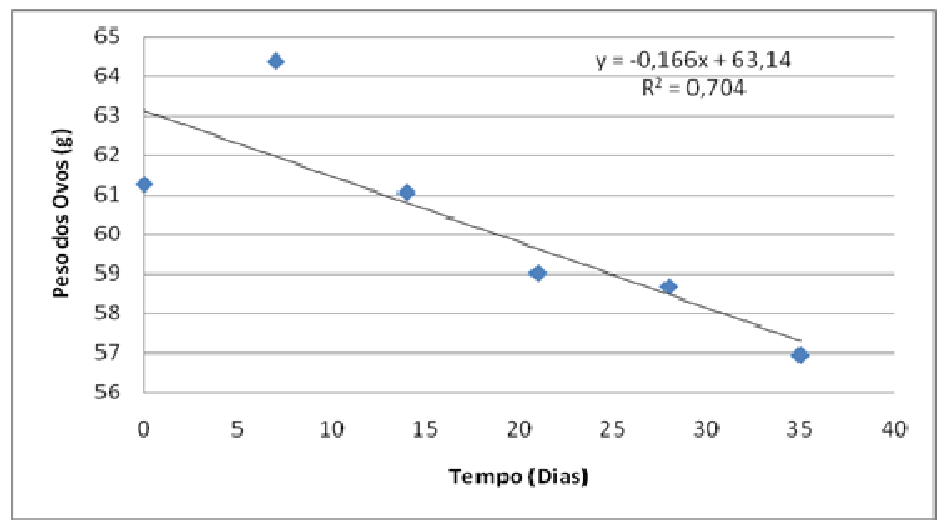

Gráfico 6: Peso dos ovos (g) armazenados em geladeira pincelados com óleo mineral no período de 35 dias. 
SFACIOTTE, R.A.P. et al. Efeito do período de armazenamento, local e tipo de tratamento sobre a qualidade de ovos brancos para consumo humano. PUBVET, Londrina, V. 8, N. 19, Ed. 268, Art. 1782, Outubro, 2014.

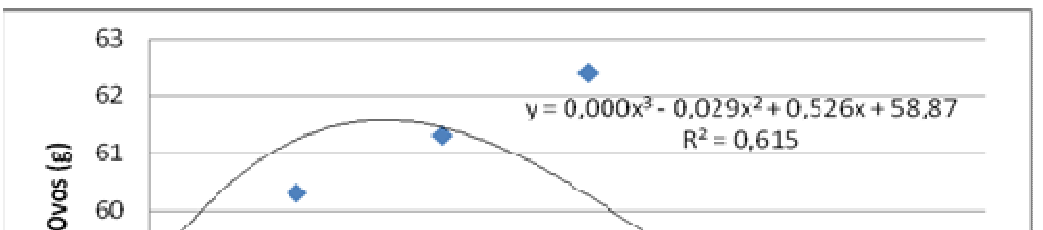

Quanto à altura e largura da gema (tabela 2), podemos observar que em temperatura ambiente, as mesmas apresentaram um diminuição e um aumento respectivamente em todos os tipos de tratamento $(P \leq 0,05)$ (gráfico 8 e 9), corroborando com Siebel e Souza-Soares (2004) que, de acordo com os autores, em temperaturas mais altas de armazenamento ocorre uma passagem de água da clara para gema devido a pressão osmótica, o que acarretaria no aumento da largura da gema. Esses dados, somados aos encontrados na tabela 1 (peso do ovo e altura do albúmen), mostram que houve uma piora na qualidade interna dos ovos armazenados em temperatura ambiente, condizendo com Wardyet al. (2010), que diz que, como todo produto de origem animal, o ovo é perecível, e começa a perder sua qualidade logo após a oviposição, especialmente na ausência de métodos adequados de armazenamento. 
SFACIOTTE, R.A.P. et al. Efeito do período de armazenamento, local e tipo de tratamento sobre a qualidade de ovos brancos para consumo humano. PUBVET, Londrina, V. 8, N. 19, Ed. 268, Art. 1782, Outubro, 2014.

Tabela 2 - Altura e largura da gema $(\mathrm{mm})$ de ovos armazenados em geladeira e ambiente, submetidos a diferentes tratamentos (lavados, não lavados e pincelados com óleo mineral) por um período de 35 dias

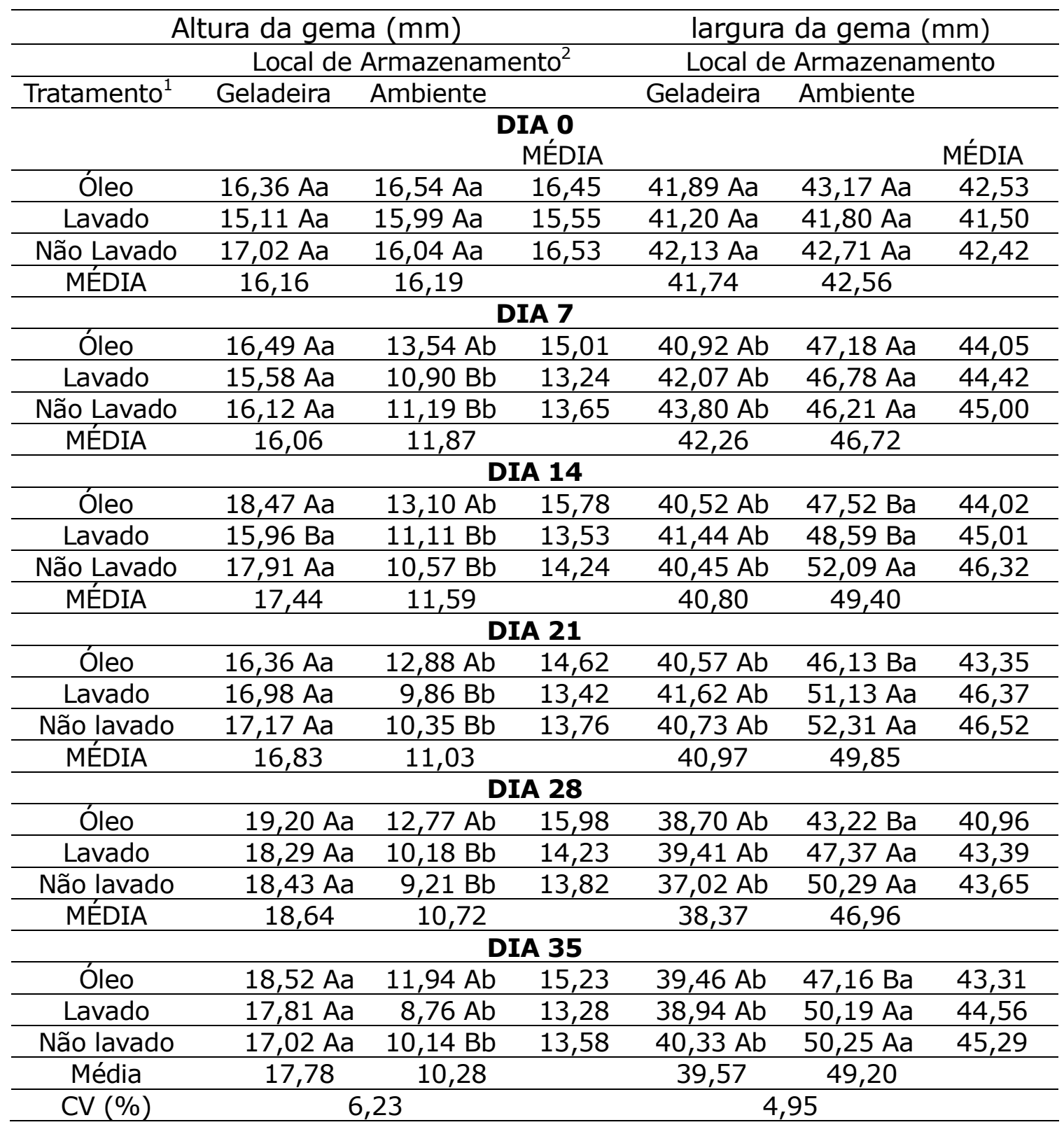

${ }^{1}$ Médias seguidas de mesma letra maiúscula, em cada coluna, não diferem entre si pelo teste de Tukey, a 5\% de probabilidade.

${ }^{2}$ Médias seguidas de mesma letra minúscula, em cada linha, não diferem entre si pelo teste $\mathrm{F}$, a $5 \%$ de probabilidade. 
SFACIOTTE, R.A.P. et al. Efeito do período de armazenamento, local e tipo de tratamento sobre a qualidade de ovos brancos para consumo humano. PUBVET, Londrina, V. 8, N. 19, Ed. 268, Art. 1782, Outubro, 2014.

De acordo com Stadelman e Cotterill (1995), várias características de qualidade interna são perdidas com a estocagem prolongada do ovo, principalmente alterações no albúmen e na gema. Segundo Shanget al. (2004), íons $\mathrm{H}+$ presentes na gema podem ser trocados com íons alcalinos provenientes do albúmen devido ao aumento do $\mathrm{pH}$ da gema, o que poderia induzir uma desnaturação de proteínas e consequentemente aumentar a consistência da gema.

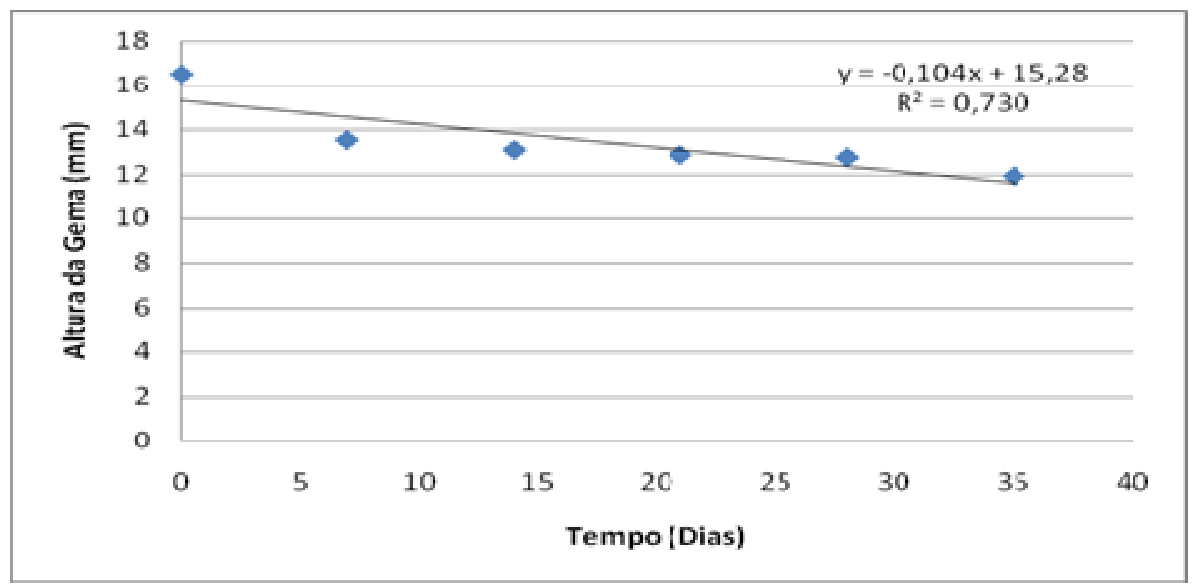

Gráfico 8: Altura da gema ( $\mathrm{mm})$ ao longo do tempo de ovos armazenados em ambiente e pincelados com óleo mineral.

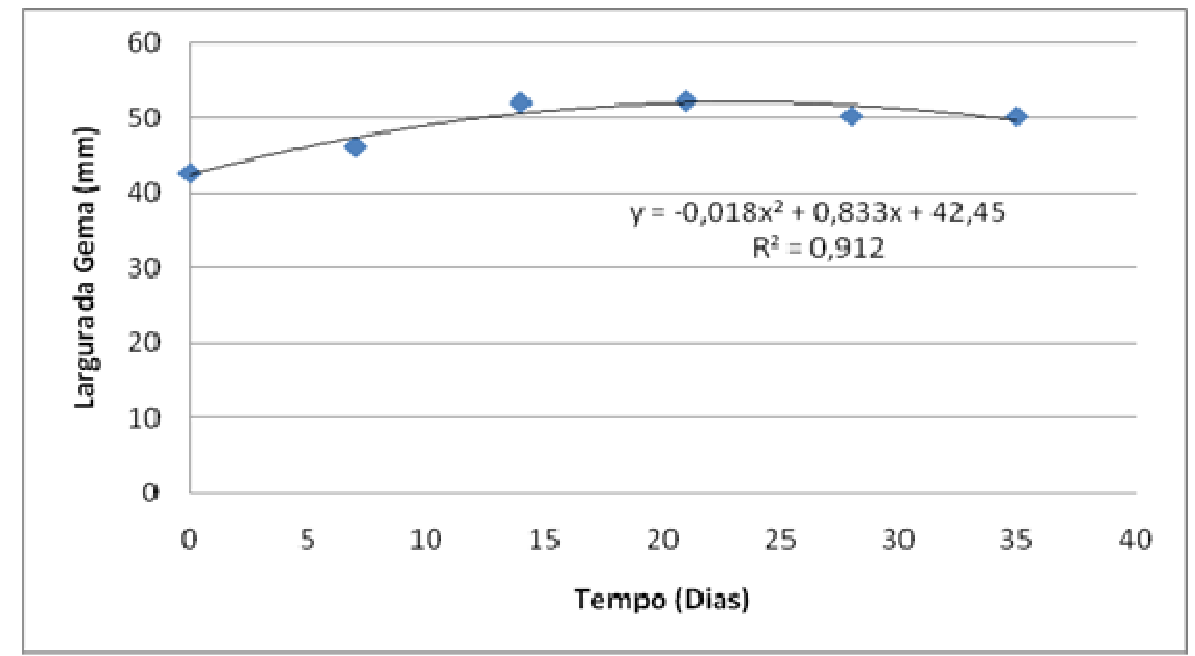

Gráfico 9: Largura da gema ao longo do tempo de ovos armazenados em ambiente, que não foram lavados, nem pincelados com óleo. 
SFACIOTTE, R.A.P. et al. Efeito do período de armazenamento, local e tipo de tratamento sobre a qualidade de ovos brancos para consumo humano. PUBVET, Londrina, V. 8, N. 19, Ed. 268, Art. 1782, Outubro, 2014.

Na tabela 2 também podemos observar os valores encontrados da altura e largura da gema do ovo sob refrigeração e eles não sofreram alterações significativas $(P>0,05)$, indicando que não ocorreu variações na qualidade interna dos ovos (gráfico 10), resultados esses que corroboram com Alleoni e Antunes et al. (2001), Barbosa et al. (2008), Freitas et al. (2011) e Lopes et al. (2012), onde todos eles dizem que a refrigeração mantém a qualidade interna dos ovos e prolonga o tempo de validade. A conservação dos ovos em temperatura ambiente pode influenciar negativamente a altura e largura da gema, sendo que a refrigeração minimiza essa variação, fato esse comprovado por Garcia et al. (2010).

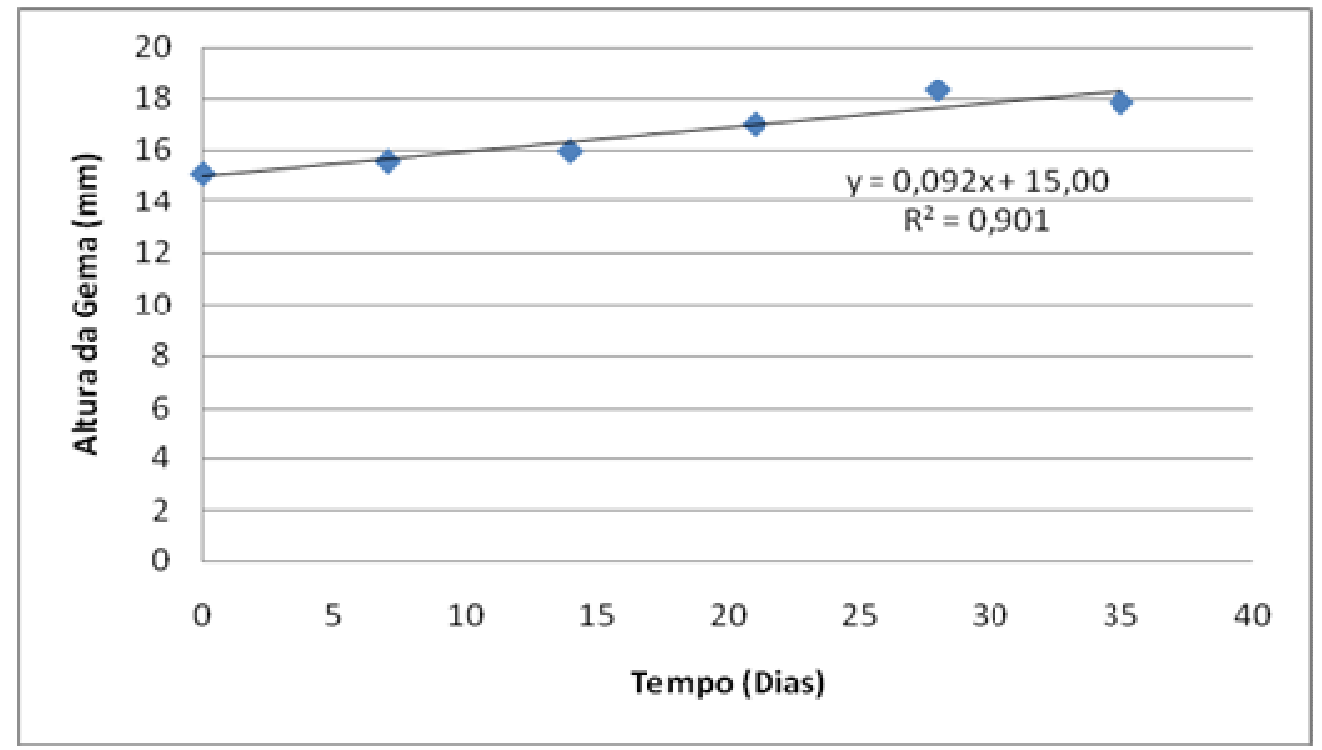

Gráfico 10: Altura da gema (mm) ao longo do tempo de ovos armazenados em geladeira e lavados com água corrente.

Quando comparado os resultados entre ovos armazenados em temperatura ambiente e ovos armazenados na geladeira, podemos perceber que os ovos não lavados com água corrente e nem pincelados com óleo mineral diferiram quantoao peso e altura da gema $(P \leq 0,05)$ na ultima semana de análise,já a altura do albúmen e a largura da gema (gráfico 11) não demonstraram efeito $(P>0,05)$.No entanto, Lopeset al. (2012) não 
SFACIOTTE, R.A.P. et al. Efeito do período de armazenamento, local e tipo de tratamento sobre a qualidade de ovos brancos para consumo humano. PUBVET, Londrina, V. 8, N. 19, Ed. 268, Art. 1782, Outubro, 2014.

encontraram diferença no peso de ovos armazenados em temperatura ambiente e refrigerados por 35 dias.

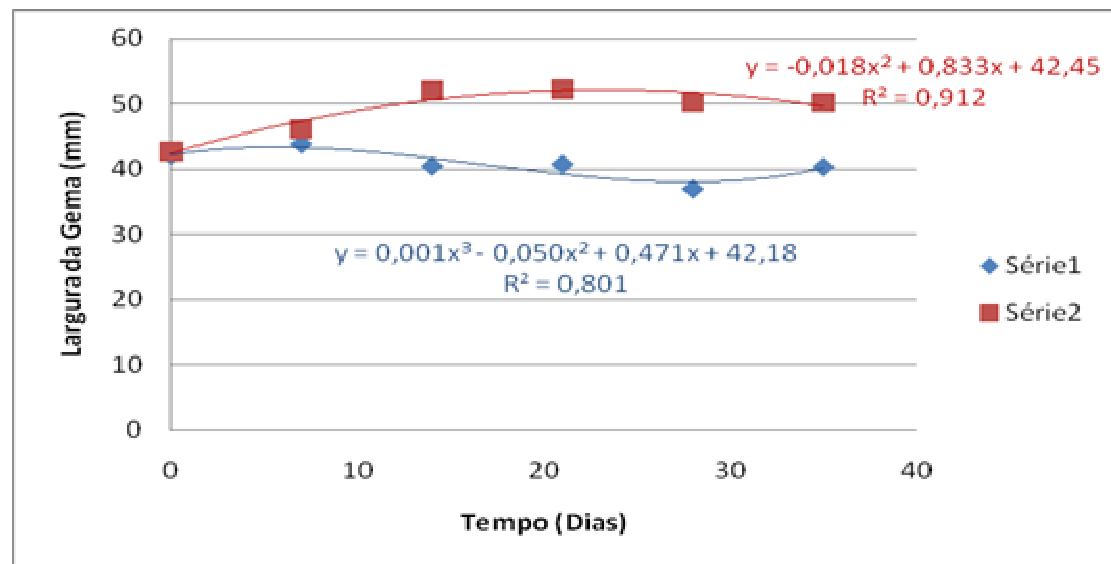

Gráfico 11: Comparação das variações da largura da gema $(\mathrm{mm})$ dos ovos não Lavados com água corrente e nem pincelados com óleo, armazenados em geladeira e ambiente.

* Série 1: Ovos armazenados em geladeira

Série 2: Ovos armazenados em ambiente

Segundo Moura et al. (2008), o tempo de prateleira dos ovos "in natura" é maior naqueles que ficaram sobre refrigeração, em concordância, Carvalho et al. (2003), relatam que a vida útil dos ovos armazenados a temperatura ambiente é menor em relação aos ovos refrigerados, dados esses que corroboram com o encontrado no presente estudo.

O grupo de ovos que foram tratados com óleo mineral não demonstraram alterações no peso, altura do albúmen e largura da gema $(P>0,05)$, porém a partir da $2^{\circ}$ semana de análise a altura da gema foi menor $(P \leq 0,05)$ nos ovos armazenados no ambiente.Waimaleongora-Eket al. (2009) observaram que a aplicação de óleo mineral na casca de ovos degalinha reduziu a perda de peso e prolongou a vida de prateleirapor mais três semanas comparado com ovos não revestidos, resultados esses semelhantes ao encontrados no presente estudo.

Os ovos lavados não apresentaram $(P>0,05)$ efeito para o peso e largura da gema (gráfico 12), contudo, a altura da gema foi menor $(P>0,05)$ no ambiente a partir da segunda semana de análise,assim como a altura do albúmen (gráfico 13) a 
SFACIOTTE, R.A.P. et al. Efeito do período de armazenamento, local e tipo de tratamento sobre a qualidade de ovos brancos para consumo humano. PUBVET, Londrina, V. 8, N. 19, Ed. 268, Art. 1782, Outubro, 2014.

partir da segunda semana também teve uma diminuição em temperatura ambiente, fato esse explicado pelos autores Scott e Silversides (2000) que encontraram respostas semelhantes ao armazenarem ovos à temperaturaambiente, e, observaram que devido a estocagem dos ovos a essa temperatura ocorreu um aumento do $\mathrm{pH}$ do albúmen e consequentemente a diminuição de sua altura.

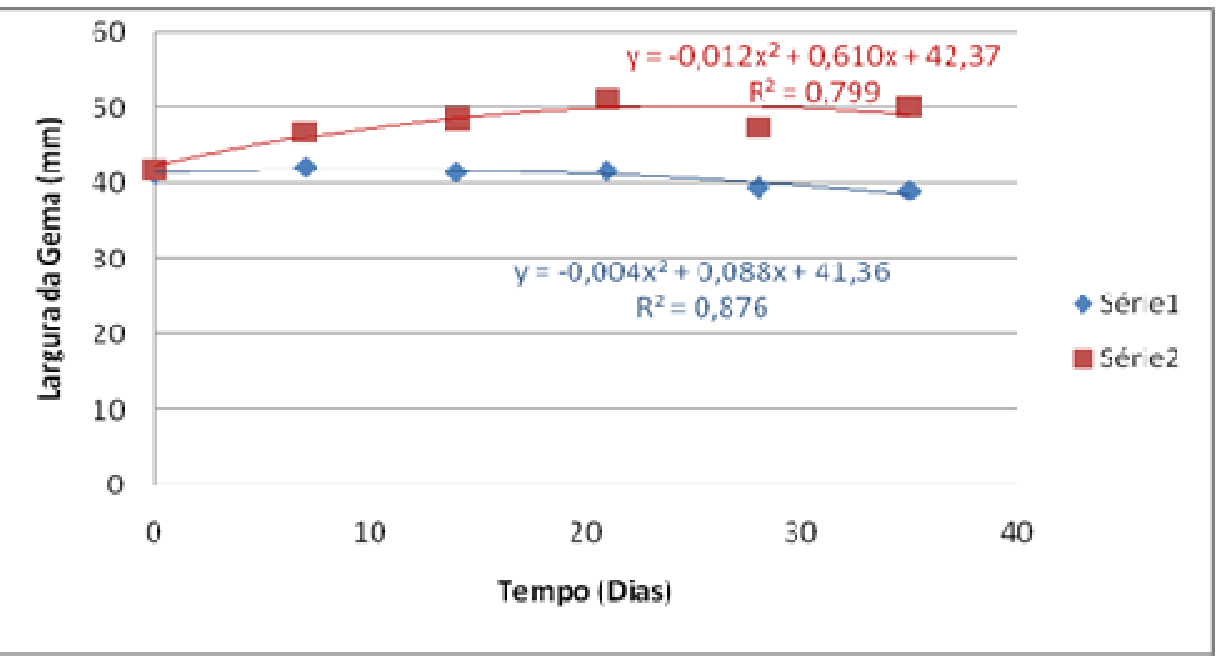

Gráfico 12: Comparação das variações da largura da gema $(\mathrm{mm})$ de ovos lavados com água corrente, armazenados em geladeira e ambiente.

* Série 1: Ovos armazenados em geladeira

Série 2: Ovos armazenados em ambiente

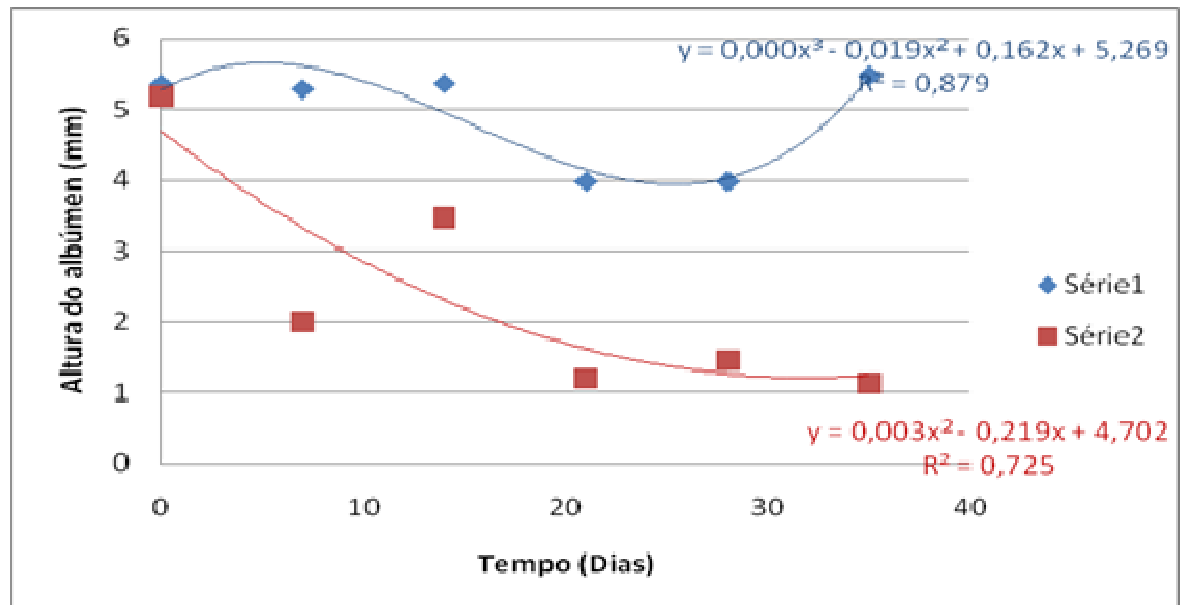

Gráfico 13:Comparação das variações da altura do albúmen $(\mathrm{mm})$ de ovos lavados com água corrente, armazeados em geladeira e ambiente.

* Série 1: Ovos armazenados em geladeira

Série 2: Ovos armazenados em ambiente 
SFACIOTTE, R.A.P. et al. Efeito do período de armazenamento, local e tipo de tratamento sobre a qualidade de ovos brancos para consumo humano. PUBVET, Londrina, V. 8, N. 19, Ed. 268, Art. 1782, Outubro, 2014.

Nesse estudo, observou-se que independente dos tratamentos (ovos lavados, não lavados e pincelados com óleo mineral), os ovos conservados em geladeira foram superiores $(P \leq 0,05)$ em qualidade para altura da gema (gráfico 14) e altura do albúmen, comparando com o ambiente. Para a largura da gema (gráfico 15) e o peso dos ovos, os efeitos foram variados, uma vez que o tempo de estocagem também foi relevante para essas variáveis. Esses resultados estão de acordo com os obtidos por Moura et al. (2008) e Marinho(2011) que encontraram efeito do tempo de estocagem sobre a perda peso de ovosde codornas japonesas. Resultados semelhantes foram obtidos em estudos realizados por Jones eMusgrove (2005), Barbosa et al. (2008) e Garcia et al. (2010) com ovos comerciais depoedeiras.

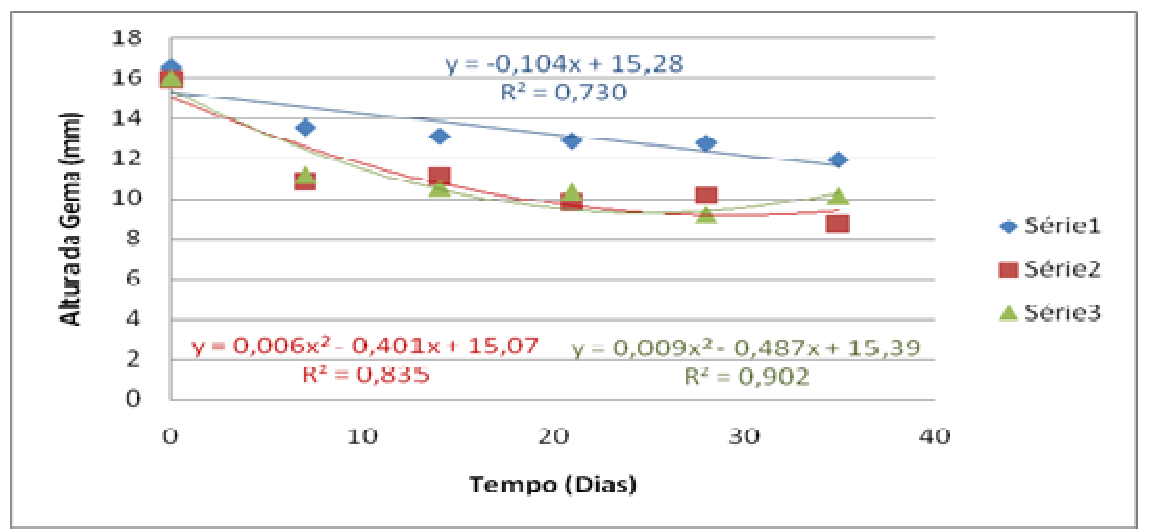

Gráfico 14: Comparação das variações da altura da gema $(\mathrm{mm})$ de ovos (pincelados com óleo, lavados com água e não pincelados e não lavados), conservados em ambiente.

*Série 1: ovos pincelados com óleo

Série 2: ovos lavados com água corrente

Série 3: ovos não lavados e não pincelados com óleo 
SFACIOTTE, R.A.P. et al. Efeito do período de armazenamento, local e tipo de tratamento sobre a qualidade de ovos brancos para consumo humano. PUBVET, Londrina, V. 8, N. 19, Ed. 268, Art. 1782, Outubro, 2014.

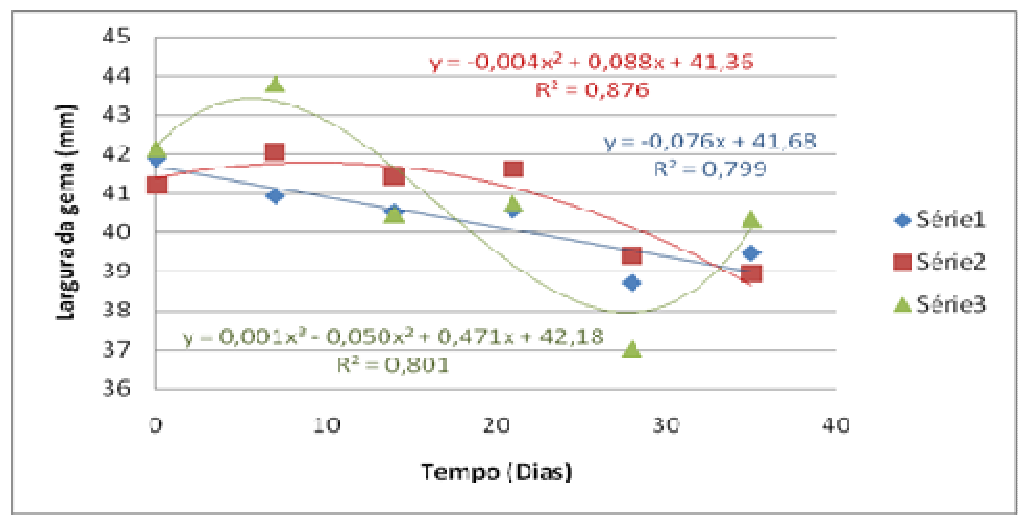

Gráfico 15:Comparação das variações da largura da gema $(\mathrm{mm})$ de ovos(pincelados com óleo, lavados com água e não pincelados e não lavados), conservados em geladeira.

* Série 1: ovos pincelados com óleo Série 2: ovos lavados com água corrente Série 3: ovos não lavados e não pincelados com óleo

Com isso, assim como dito por Souza-Soares e Siewerdt (2005), o armazenamento tem papel importantíssimo na conservação dos ovos, pois é neste período que ocorrem trocas de origem física, química e microbiana; portanto, o tempo e atemperatura devem estar ligados a outros fatores para garantir, assim, uma boa preservação, assim, concluiu-se por meio deste ensaio que os ovos perdem suas propriedades qualitativas ao longo do tempo, caso não sejam conservados em condições de baixa temperatura, independente se forem pincelados com óleo, lavados com água corrente ou não. E a conservação dos ovos em ambiente não é recomendado para a manutenção da qualidade interna dos mesmos.

\section{REFERÊNCIAS BIBLIOGRÁFICAS}

ALLEONI, A.C.C.; ANTUNES, A.J.Unidade haugh como medida daqualidade de ovos de galinha armazenados sob refrigeração.ScientiaAgricola, v.58, n.4, p.681-685, 2001.

ANDRADE, A.N. Effects of high environmental temperature and diets on egg shell quality andperformance of laying hens. 1975. 114 f. Dissertação ("Doctor of Philosophy") PurdueUniversity, Maryland, U.S.A. 1975. 
BARBOSA, N.A.A.; SAKOMURA, N.K.; MENDONÇA, M.O.; FREITAS, E.R. FERNANDES, J.B.K. Qualidadede ovos comerciais provenientes depoedeiras comerciais armazenados sobdiferentes tempos e condições de ambientes. ARS Veterinária, v.24, n.2,p.127-133, 2008.

BERARDINELLI, A.; DONATI, V.; GIUNCHI, A.; GUARNIERI, A.; RAGNI, L.Effects of transport vibrations on quality indices of shell eggs.BiosystemsEngineering, v. 86, n. 4, p. 495-502, 2003.

CANER, C. Whey protein isolate coating andconcentration effects on egg shelf life. Journal of theScience of Food and Agriculture, New York, v. 85, n. 13, p. 2143-2148, 2005.

CARVALHO, F.B.C.; STRINGHINI, J.H.; JARDIM FILHO, R.M.;LEANDRO M.S.N.; PÁDUA. J.T.;DEUS, H.A.S.B. Influência da conservação e do período de armazenamento sobre a qualidadeinterna e de casca de ovos comerciais.Revista Brasileira de Ciência Avícola,v.18, p.100, 2003. Supl. 5.

CRUZ, V.C.; FERNANDEZ, I.B.; TRAVA, C.M.; SEDANO, A.A.; PICCININ, A.; MAIOLI,M.A. Suplementação dietética com Selênio e Zinco orgânicos na qualidade interna e externa de ovos de codornas japonesas submetidas a estresse térmico. In: 46a Reunião Anual da SociedadeBrasileira de Zootecnia, Maringá. Anais... Maringá, 2009.

FIGUEIREDO, T. C.; CANÇADO, S. V.; VIEGAS, R. P.; RÊGO, I. O. P.; LARA, L. J. C. ;SOUZA, M. R.; BAIÃO, N. C. Qualidade de ovos comerciais submetidos a diferentes condições dearmazenamento. Arquivo Brasileiro de Medicina Veterinária e Zootecnia, v. 63, n. 3, p. 712-720, 2011.

FREITAS, L. W.; PAZ, I. C. L.; GARCIA, R. G.; CALDARA, F. R.; SENO, L. O.; FELIX, G. A.;LIMA, N. D. S.; FERREIRA, V. M. O. S.; CAVICHIOLO, F. Aspectos qualitativos de ovoscomerciais submetidos a diferentes condições de armazenamento. Revista Agrarian, $v$. 4, n. 11 , p. 66-72, 2011.

GARCIA, E.R.M.; ORLANDI, C.C.B.;OLIVEIRA, C.A.L.; CRUZ, F.K.;SANTOS, T.M.B.; OTUTUMI, L.K. Qualidade de ovos de poedeiras semipesadas armazenados em diferentestemperaturas e períodos de estocagem.Revista Brasileira de Saúde eProdução Animal[online], v.11, n.2,p.505-518, 2010.

JONES, D.R.; MUSGROVE, M.T. Effects of extended storage on egg quality factors.Poultry Science, v.84,n.11, p.1774-1777, 2005.

LEANDRO, N.S.M.; DEUS, H.A.B. de;STRNGHINI, J.H.; CAFÉ, M.B.;ANDRADE, M.A.; CARVALHO, F.B.de;Aspectos de qualidade interna e externa de ovos comercializados emdiferentes estabelecimentos na região de Goiânia. Ciência Animal Brasileira,v.6, n.2, p. 71-78, 2005.

LLOBET, J. A. C., PONTES, M. P., GONZALEZ, F. F. Factores que afectan a lacalidaddelhuevo. In: Producción de huevos. Barcelona, Espanha: Tecnograf S.A., p. 255-274, 1989.

LOPES, L . L. A.; SILVA, Y. L.; NUNES, R. V.; TAKAHASHI, S. E.; MORI, C. nfluência dotempo e das condições de armazenamento na qualidade de ovos comerciais. Revista eletrônica de Medicina Veterinária. n. 18, 2012.

MARINHO, A. L. Qualidade interna e externa de ovos de codornas (Coturnix japônica) armazenados em diferentes temperaturas e períodos de estocagem. Dissertação (Mestrado em Zootecnia) - Universidade Federal de Alagoas, Rio Largo, 2011. 
MENDES, F. R. Qualidade física, química e microbiológica de ovos lavados armazenados sobduas temperatuas e experimentalmente contaminados com Pseudomonasaeruginosa. 2010. 72f. Dissertação (Mestrado em Ciência Animal) - Escola de Veterinária, Universidade Federal deGoiás, Goiânia, 2010.

MORENG, R. E.; AVENS, J. S. Anatomia e fisiologia das aves. In: Ciência e produção de aves.Tradução Nair MassakoKatayma Ito. São Paulo: Roca, cap. 3, p. 43-75, 1990

MOURA, A.M.A.; OLIVEIRA, N.T.E.;THIEBAUT, J.T.L.; MELO, T.V. Efeito da temperatura de estocagem e do tipo deembalagem sobre a qualidade interna de ovos de codornas japonesas (Coturnixjaponica). Ciência e Agrotecnologia, v.32, n.2, p.578-583, 2008.

ORDÓNEZ, J.A. Ovos e produtos derivados. In: Tecnologia de alimentos: Alimentos de origemanimal. Porto Alegre: Artmed, p. 269-279, 2005.

PASCOAL, L.A.F.; BENTO JUNIOR, F.A.; SANTOS, W.S.; SILVA, R.S.; DOURADO, L.R.B.; BEZERRA, A.P.A.Qualidade de ovos comercializados em diferentes estabelecimentos na cidade de Imperatriz-MA. Revista Brasileira deSaúde Produção Animal, v.9, n. 1, p. 150-157, 2008.

POMBO, C. R. Efeito do Tratamento Térmico de Ovos Inteiros na Perda de Peso eCaracterísticas de Qualidade Interna. 2003. 74f, Dissertação (Mestrado em Higiene Veterinária e Processamento Tecnológico de Produtos de Origem Animal) Faculdade de Veterinária.UniversidadeFederal Fluminense, Niterói- RJ, 2003.

RÊGO, I.O.P.; CANÇADO, S.V; FIGUEIREDO, T.C.; MENEZES, L.D.M.; OLIVEIRA, D.D.;LIMA, A.L.; CALDEIRA,L.G.M.; ESSER, L.R. Influência do período de armazenamento naqualidade do ovo integral pasteurizado refrigerado. Arquivo Brasileiro de Medicina Veterinária eZootecnia, v. 64, n. 3, p.735-742, 2012.

SANTOS, M.S.V.; ESPÍNDOLA, G.B.;LÔBO, R.N.B.; FREITAS, E.R.;GUERRA, J.L.L.; SANTOS, A.B.E.Efeito da temperatura e estocagem em ovos. Ciência e Tecnologia deAlimentos, v.29, n.3, p.513-517, 2009.

SCATOLINI-SILVA, A. M.; BORBA, H.; GIAMPIETRO-GANECO, A.; SOUZA, P. A.; BOIAGO, M. M.; MELLO, J. L. M.; VAZ, A. B. S. Qualidade física de ovos armazenados emdiferentes condições de embalagens sob temperatura ambiente. Arquivos de Zootecnia, v. 62, n. 238, p. 247-254, 2013.

SCOTT, T. A.; SILVERSIDES, F. G.The effect of storage and strain of hen on egg quality.Poultry Science, Champaign, v. 79, p. 1725-1729, 2000.

SEIBEL, N. F. Transformações bioquímicas durante o processamento do ovo. In: SOUZASOARES, L. A.; SIEWERDT, F. Aves e ovos. Pelotas: UFPEL, p 77-90, 2005.

SHANG, X.G.; WANG, F.L.; LI, D.F.;YIN, D.J.; LI, J.Y. Effects of dietary conjugated linoleic acid on theproductivity of laying hens and eggquality during refrigerated storage.Poultry Science, v.83, n.10, p.1688-1695, 2004.

SIEBEL, N.F.; SOUZA-SOARES, L.A.Efeito do resíduo de pescado sobre ascaracterísticas físicas e químicas de ovosde codornas armazenados em diferentes períodos. Semina: Ciências Agrárias,v.25, n.1, p.35-44, 2004. 
SILVA, A. L. S.; BROLEZE, L. F.; SIDOU, L. F.;HENRIQUES, C. Y. H.; SPANOL, T. M.; AUGUSTO,P. E. D. Qualidade de ovos recobertos com fécula de mandioca. Tecnologia \& Ciência Agropecuária, João Pessoa, v. 4, n. 3, p. 43-46, 2010.

SILVERSIDES, F. G., TWIZEYIMANA, F., VILLENEUVE, P. Research note: a study relating tothe validity of the Haugh unit correction for egg weight in fresh eggs. Poultry Science, Champaing, v. 72, p.760-764, 1993.

SOLOMON, S.E Egg and Eggshell quality. Iowa: Iowa States University Press, 1997, 149p.

SOUSA-SOARES, L. A.; SIEWERDT, F. Aves e ovos. Pelotas: Ed. da Universidade UfPEL,2005. 138 p.: il.

STADELMAN, W.J.; COTTERILL, O.J. Egg science and technology. New York/London: Food Products Press, 1995. 323p.

UNIÃO BRASILEIRA DOS AVICULTORES - UBA. Relatório anual 2013, [online], 2013.Disponível em:<http://www.ubabef.com.br/files/publicacoes/732e67e684103de4a2117dda9ddd280a.pdf >. Acesso em: 26 fev. 2013.

USDA.UNITED STATES DEPARTMENT OF AGRICULTURE.Egg-Grading Manual.Washington. n.75, 2000.Disponível

em:<http://www.ams.usda.gov/AMSv1.0/getfile?dDocName=STELDEV3004502>. Acessoem: 13 fev. 2014.

WAIMALEONGORA-EK, P.; GARCIA, K.; NO, H.K.;PRINYAWIWATKUL, W.; INGRAM,D. Selected quality and shelf-life of eggs coated with mineral oil with different viscosities.Journal of FoodScience, v.74, p.423-429, 2009. Supl.

WARDY, W.; TORRICO, D.D.; NO, H.K.; PRINYAWIWATKUL, W.;SAALIA, F.K. Edible coating affectsphysic-functional properties and shelf life of chicken eggs during refrigerated and room temperature storage. International Journal of Food Sciencee Technology, v.45, p.26592668,2010 .

WORLD POULTRY: Ranking the world's major egg producers. Newsletter,January. 2012. Disponível em:http://www.worldpoultry.net/Home/General/2012/1/Ranking-the-worldsmajoregg-producers-WP009929W/. Acesso em: 13 jan. 2014. 